\title{
Relation of environmental problems with human health in agro-extractive settlement projects in the Eastern Amazon
}

\section{Danilo José Franco Coutinho' ${ }^{1}$, Elias José Tuma Filho²}

\author{
${ }^{1,2}$ Instituto Nacional de Colonização e Reforma Agrária. Rodovia Murutucum s/nº, Souza - Belém-PA - Brasil.
}

Email: danilo.coutinho@blm.incra.gov.br, elias.tuma@blm.incra.gov.br

Received: February 16th, 2017

Accepted: April $17^{\text {th }}, 2017$

Published: June $30^{\text {th }}, 2017$

Copyright (O2016 by authors and Institute of Technology Galileo of Amazon (ITEGAM) This work is licensed under the Creative Commons Attribution International License (CC BY 4.0).

http://creativecommons.org/lic enses/by/4.0/ (c) (i) (2)(2) Opea Actes:

\begin{abstract}
Risks to human health are closely related to environmental damage resulting from anthropization. Agroextractive Settlement Projects are important geographical territory spaces from Pará. The present work had as objective reporting changes on human health influenced by environmental factors in this mode of settlement. They analyzed the health changes related to existing environmental problems in six projects, both located in Cametá, Pará State. Using database software Excel spreadsheets for the correlation of the health and environmental data. Of the total of $92779 \%$ use water bodies extraction for human consumption of water, $70 \%$ did not make any treatment or just the strainer. With regard to sanitation, in $87 \%$ of households there is treatment of human waste. As for the fate of the residential waste $95 \%$ organic and not burn the $96 \%$ employ the organic animal feed. It was concluded that inappropriate environmental practices compromise human health in these islands.
\end{abstract}

Keywords: Environment, human health, agro-extractive settlement projects, traditional populations.

\section{Relação de problemas ambientais com a saúde humana em projetos de assentamento agroextrativista na Amazônia Oriental}

\begin{abstract}
RESUMO
Riscos à saúde humana estão estreitamente relacionados aos danos ambientais resultantes da antropização. Projetos de Assentamento Agroextrativista são importantes espaços geográficos do território paraense. O presente trabalho teve como objetivo relatar modificações na saúde humana influenciadas por fatores ambientais nessa modalidade de assentamento. Analisaram-se as alterações de saúde relacionadas a problemas ambientais existentes em seis Projetos, todos localizados em Cametá, estado do Pará. Utilizou-se banco de dados de planilhas do software Excel para a correlação dos dados de saúde e ambientais. Do total de 928 extrativistas, 83\% utilizam corpos hídricos para consumo humano da água, $70 \%$ não fazem tratamento algum ou apenas a coagem. No tocante ao es gotamento sanitário, em $85 \%$ das residências não há tratamento dos dejetos humanos. Quanto ao destino do lixo residencial, $87 \%$ queimam o não orgânico e $88 \%$ empregam o orgânico para alimentação animal. Concluiu-se que práticas ambientais inadequadas comprometem a saúde humana nestas ilhas.
\end{abstract}

Palavras Chaves: meio ambiente, saúde humana, projetos de assentamento agroextrativista, populações tradicionais

\section{INTRODUÇÃO}

A Amazônia Brasileira tem sido estudada em seus mais diversos aspectos, e dentre eles um dos mais importante se refere aos fatores ambientais, uma vez que estes afetam diretamente a vida dos habitantes desse bioma. Igualmente relevante é a saúde humana das populações inseridas nos muitos ecossistemas dessa região.
As populações rurais da amazônia brasileira por vezes são expostas a condições ambientais das mais variadas, tais como contaminação de águas superficiais, alimentos e do solo. O contato direto dessas pessoas com essa problemática ambiental pode ocasionar várias enfermidades, como diarréia, infecção gastrointestinal, hepatite, doença de pele, verminose, dor no corpo, dor de cabeça, febre, anemia, vômito, hemorragia, amebíase, dermatite crônica. 
Projeto de Assentamento Agroextrativista (PAE) é uma modalidade de as sentamento destinado a populações tradicionais, para exploração de riquezas extrativas, por meio de atividades economicamente viáveis, socialmente justas e ecologicamente sustentáveis, introduzindo a dimensão ambiental às atividades agroextrativis tas [1].

No Brasil, o Instituto Nacional de Colonização e Reforma Agrária - INCRA é uma autarquia federal criada com a missão de realizar a reforma agrária, manter o cadastro nacional de imóveis rurais, administrar as terras públicas da União e contribuir para o desenvolvimento rural sustentável [2]. Nas suas diretrizes possuia criação e implantação de as sentamentos rurais sustentáveis alémda busca da qualificação dos assentamentos rurais [3].

A degradação ambiental tem sido motivo de preocupação da comunidade científica, uma vez que a inércia humana diante das recentes constações resultará em consequências danosas irreversíveis para diversas formas de vida existentes no mundo.

A realização de estudos que apontem a relação da degradação ambiental com a saúde de comunidades rurais é de extrema importância para a sociedade, uma vez que as informações geradas com as pesquisas servirão de subsídios para atores direta ou indiretamente envolvidos com saúde pública no Brasil, em especial a Amazônia Legal.

O estado do Pará possui o maior número de PAE's criados em termos nacionais [4]. Na área de atuação da Superintendência Regional do INCRA no Pará esta modalidade de assentamento se destaca quantitativamente em relação às demais, conforme se observa no gráfico 1, evidenciando-se assim a importância de se estudar temas que envolvam as comunidades residentes nestas áreas.

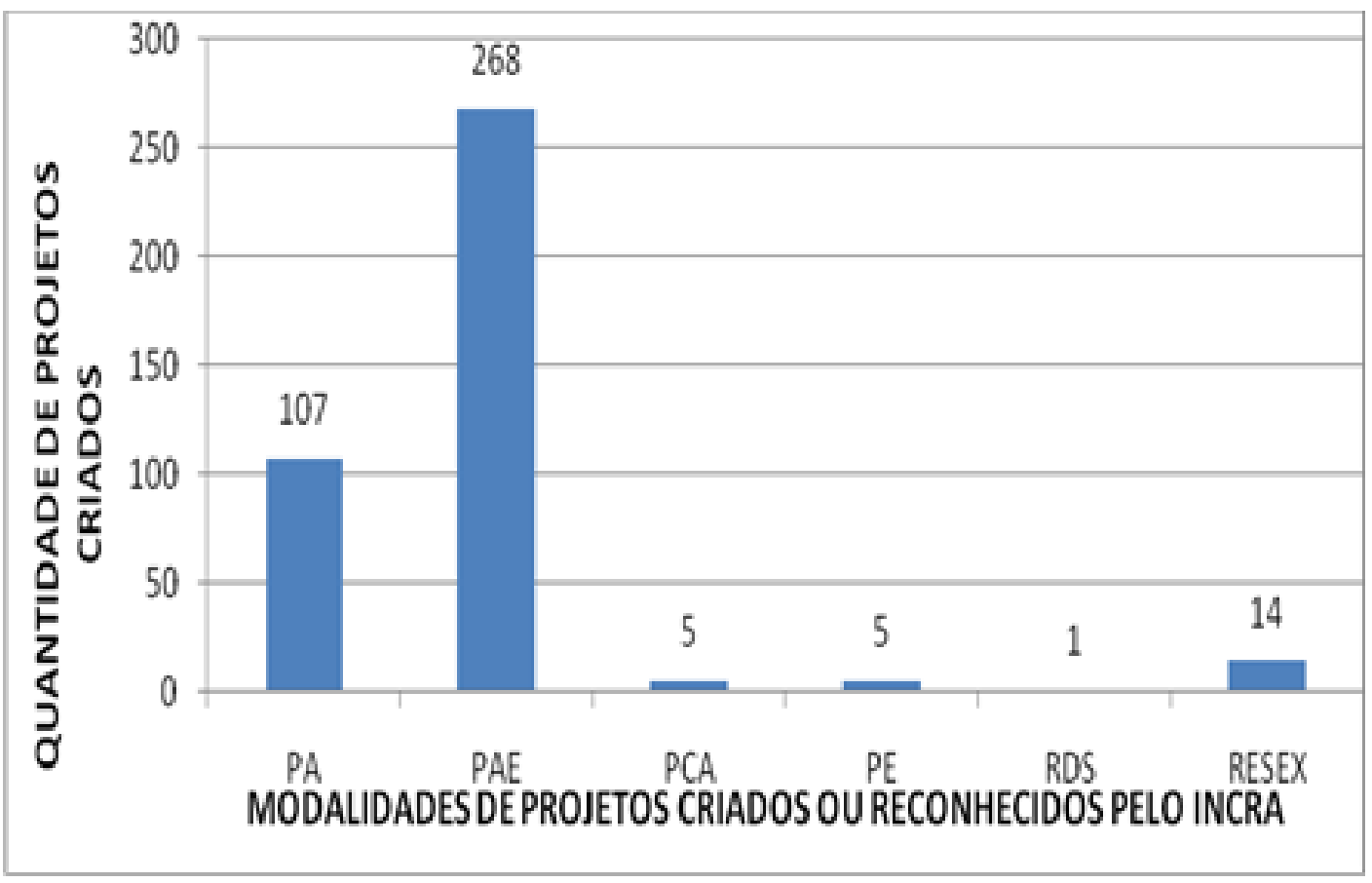

Figura 1. Gráfico Quantitativo atual de projetos criados e/ou com famílias beneficiárias pelo INCRA SR-01.

Fonte: Sistema de Informações de Projetos de Assentamento da Reforma Agrária - INCRA (2016).

No presente estudo foi analis ada a alteração do estado de saúde decorrente de aspectos ambientais, especialmente o saneamento básico em PAE, tendo como objetivo contribuir para o bem estar da população na Amazônia a partir do conhecimento dos processos de antropização.

\section{REVISÃO BIBLIOGRÁFICA}

Entre múltiplos aspectos que oferecem risco à saúde humana está a interface coma questão ambiental, pela antropização de grandes áreas [5]. Diversos trabalhos já foram publicados abordando a relação saúde x meio ambinete. [6] analisaram teores de mercúrio (Hg) e arsênio (As) existentes em seres humanos em localidades da Amazônia.

Para [7] afirmam que a expansão do agronegócio resulta emcondições degradantes aos trabalhadores rurais que atuamnesse segmento produtivo aumentando a quantidade de intoxicações e acidentes de trabalho.

O trabalho de [8] mostrou risco real aos turistas de uma praia localizada no nordeste brasileiro, expostos à esquis tos somose mansoni, doença transmitida por Biomphalaria glabrata, caramujo com proliferação devido às intervenções humanas ao meio ambiente.

Para [9] concluíram que o uso de água de má qualidade em irrigação de cultivos vegetais pode influenciar diretamente a contaminação dos alimentos, acarretando em sérias implicações à saúde dos consumidores.

Notam-se, portanto, as múltiplas consequências à saúde humana decorrentes de alterações ambientais no meio natural existente.

\section{MATERIAIS E MÉTODOS}

Para realização da abordagem analítica, a partir de dados secundários, foram utilizadas informações coletadas pelo Instituto de Assessoria Técnica Social e Agroambiental da Amazônia (IATAM), entidade essa prestadora de serviço de Assistência Técnica e Extensão Rural (ATER), contratada pelo INCRA para este fim, com a execução de atividades voltadas aos beneficiários da Reforma Agrária, no tocante a aspectos socioambientais, culturais e econômicos das famílias residentes em projetos de assentamento agroextrativista na região do Baixo Tocantins, município de Cametá, estado do Pará. 
Fez-se uma pesquisa documental com estudo analítico, realizada no município de Cametá-Pará, com área de delimitação em seis PAE: Pacajaí II, Biribatuba, Pacajaí I, Cacoal, Jacareuá e Itaúna, como é possível ver na Figura 1. Na coleta de dados o IATAM realizou entrevistas com as famílias, aplicando
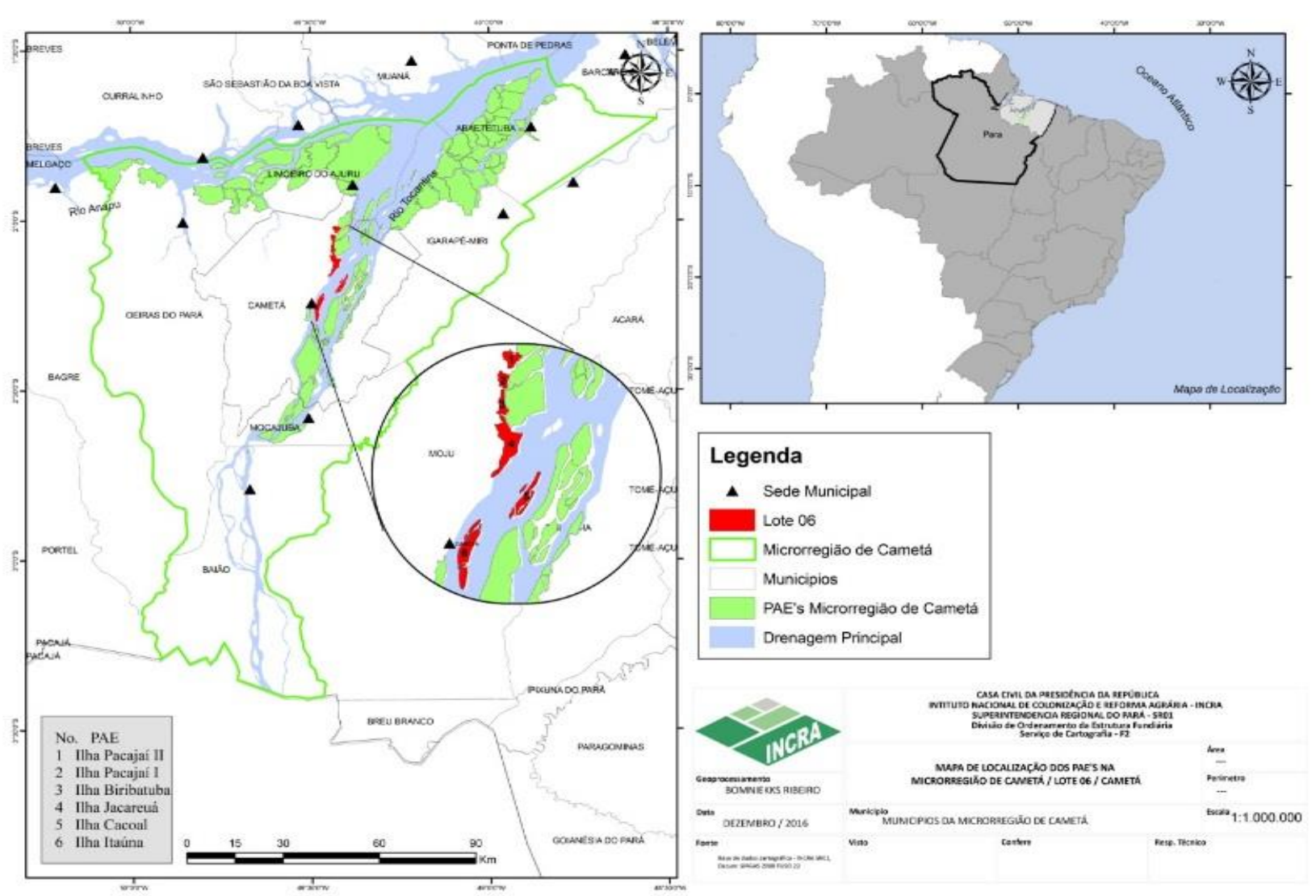

Figura 2: Mapa de Localização dos PAE’s na Microrregião de Cametá.

Fonte: INCRA, (2016).

A tabela 1 apresenta os dados de área, total de famílias entrevistadas e porcentagem da amostra utilizada para o presente estudo, essa última combom nível de significância, vis to que foram instrumento pré-estruturado denominado "questionário socioeconômico e ambiental" elaborado pelo INCRA. Para a análise utilizou-se banco de dados de planilhas do software Micros oft Excel para a correlação dos dados de saúde xambientais, a partir dos relatórios entregues pelo IATAM ao INCRA. entrevistados pelo IATAM $83,50 \%$ do total de famílias existentes numa área de 3.255,0061 ha.

Tabela 1- Dados gerais dos PAE estudados.

\begin{tabular}{c|ccccc}
\hline No & $\begin{array}{c}\text { PAE } \\
\text { (ILHA) }\end{array}$ & ÁREA (ha) & TOTAL DE FAMíLIAS & TOTAL DE ENTREVISTAS & \% DE ENTREVISTAS \\
\hline 1 & Pacajaí II & 328,8881 & 38 & 36 & 94,7 \\
2 & Biribatuba & 287,4486 & 174 & 162 & 93,1 \\
3 & Pacajaí I & 224,4334 & 57 & 49 & 86,0 \\
4 & Cacoal & 520,1800 & 298 & 253 & 84,9 \\
5 & Jacareuá & 773,5151 & 196 & 143 & 73,0 \\
6 & Itaúna & $1.120,5409$ & 336 & 275 & 81,8 \\
\hline & TOTAL & $3.255,0061$ & 1.099 & 918 & 83,5 \\
\hline
\end{tabular}

Fonte: IATAM adaptado pelos autores (2015). 
Cametá está inserido no perímetro da Amazonia Legal. Segundo [10] o referido município possui uma população total estimada de 132.515 habitantes, sendo $56 \%$ vivendo na zona rural [11].

\section{RESULTADOS E DISCUSSÕES}

A Tabela 2 apresenta dados percentuais referentes às ações da comunidade sobre o ambiente em que vivem. Para a utilização da água 69,68\% não fazem tratamento algum ou apenas a coagem e $82,30 \%$ us am recurs os hídricos de rios ou igarapés para o próprio consumo. No tocante ao esgotamento sanitário, em $87,27 \%$ das residências não há tratamento dos dejetos humanos. Quanto ao destino do lixo residencial $86,51 \%$ queimam o não orgânico e 87,37\% empregam o orgânico para alimentação animal. A falta de água potável é agravada pela contaminação de corpos hídricos por dejetos humanos, resíduos das famílias e embarcações. Isso tudo aliado à precariedade de serviços de saúde reflete na ocorrência de doenças como viroses, verminoses, infecção intestinal, problemas estomacais e outros.

Tabela 2: Ações dos moradores dos PAE sobre o meio ambiente.

\begin{tabular}{|c|c|c|c|c|c|}
\hline \multirow{3}{*}{$\begin{array}{c}\text { Projeto de } \\
\text { Assentamento } \\
\text { Agroextrativista }\end{array}$} & \multicolumn{5}{|c|}{$\begin{array}{c}\text { Quantitativo de Famílias dos PAE entrevistadas por ação sobre o meio } \\
\text { ambiente }\end{array}$} \\
\hline & \multirow{2}{*}{$\begin{array}{c}\text { Utilização } \\
\text { dos rios para } \\
\text { consumo de } \\
\text { água }\end{array}$} & \multirow{2}{*}{$\begin{array}{c}\text { Sem } \\
\text { tratamento } \\
\text { de água }\end{array}$} & \multicolumn{2}{|c|}{ Destinação do lixo } & \multirow{2}{*}{$\begin{array}{c}\text { Sem } \\
\text { tratamento } \\
\text { dos dejetos } \\
\text { humanos }\end{array}$} \\
\hline & & & $\begin{array}{l}\text { Alimentação } \\
\text { de animais }\end{array}$ & Queimado & \\
\hline PAE Ilha Biribatuba & 117 & 114 & 158 & 157 & 131 \\
\hline PAE Ilha Cacoal & 244 & 232 & 244 & 246 & 239 \\
\hline PAE Ilha Itaúna & 232 & 141 & 271 & 265 & 230 \\
\hline PAE Ilha Jacareuá & 93 & 90 & 137 & 134 & 133 \\
\hline PAE Ilha Pacajaí I & 45 & 45 & - & - & 46 \\
\hline PAE Ilha Pacajaí II & 32 & 24 & & 30 & \\
\hline Sub Total & 763 & 646 & 810 & 832 & 779 \\
\hline $\begin{array}{l}\text { Total de familias } \\
\text { entrevistadas }\end{array}$ & 918 & 918 & 918 & 918 & 918 \\
\hline $\begin{array}{c}\text { \% em relação ao } \\
\text { total de famílias } \\
\text { entrevistadas }\end{array}$ & 83,11 & 70,37 & 88,23 & 90,63 & 84,85 \\
\hline
\end{tabular}

Fonte: IATAM adaptado pelos autores, (2015).

Nas figuras 3 e 4 pode-se observar a forma de armazenamento para o consumo de água e tipo de banheiro mais frequentemente construído pelos ribeirinhos dos PAE em estudo.

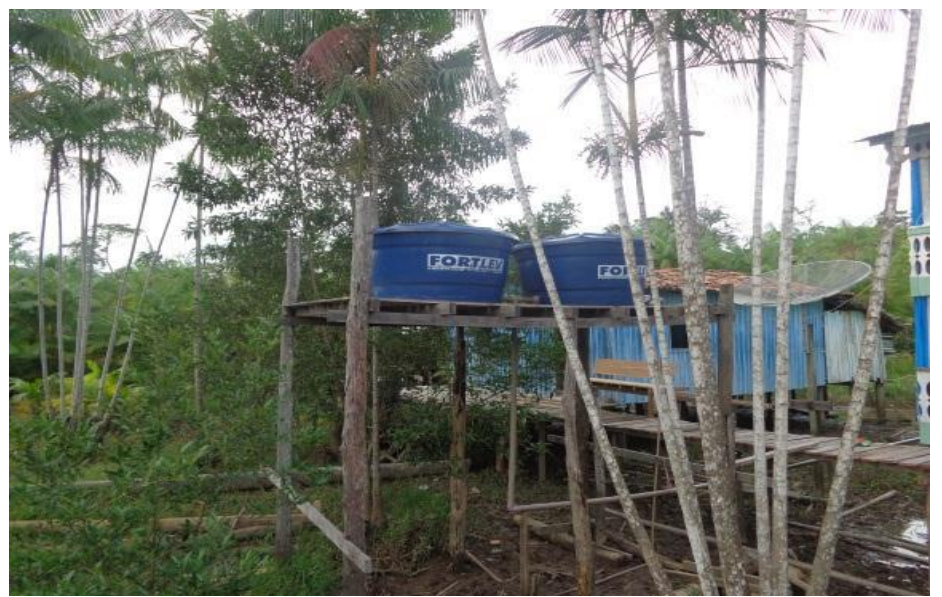

Figura 3: Água do rio acondicionada em caixas de PVC Fonte: IATAM, (2015).

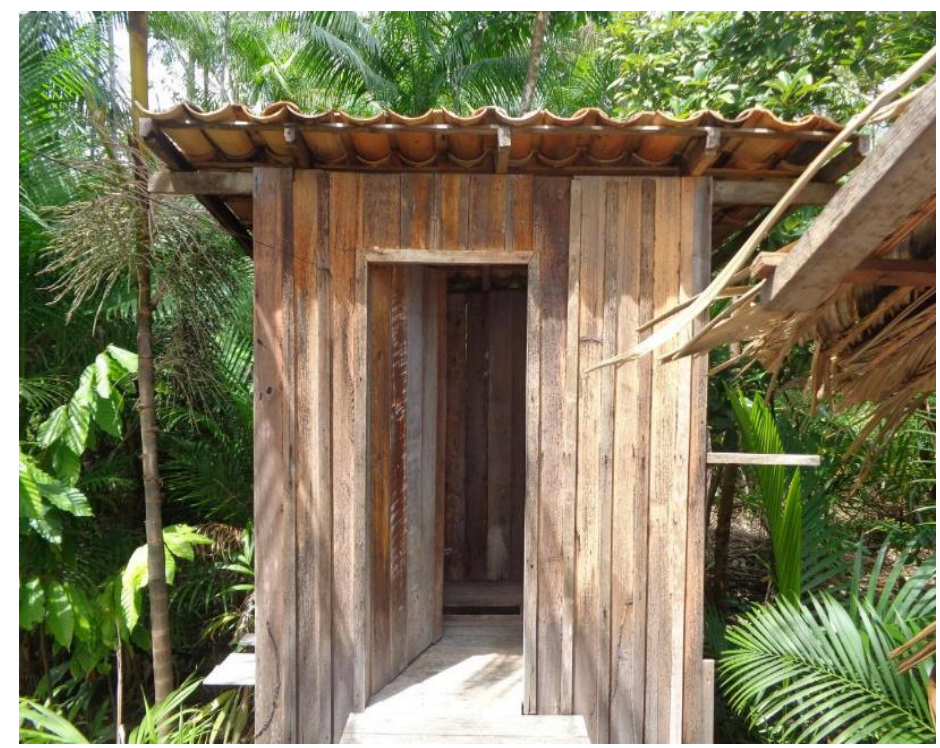

Figura 3: Tipo de banheiro utilizado pelos moradores do PAE Fonte: IATAM, (2015). 


\section{IV.1 CONSIDERAÇÕES POR PAE ESTUDADO}

\section{IV.1.1 PACAJAÍ II}

Foram entrevistadas pela prestadora de ATER IATAM 36 famílias de um total de 38 famílias assentadas com informações abaixo descritas [12].

O PAE possui uma área total de 328,8881 ha. Não há posto de saúde na comunidade.

As principais doenças existentes na ilha, de acordo comos relatos dos moradores, são hipertensão, diabetes, doenças de pele, asma, verminoses, viroses e hipertensão. Algumas dessas doenças estão intimamente ligadas às questões de falta de saneamento básico, tais como a má qualidade da água consumida ou o contato direto com a água do rio durante o banho.

Com referência à água para o uso na residência, a principal fonte é dos rios, ou seja, todas as famílias utilizam a água do rio para uso da residência, inclusive para o consumo, no entanto, algumas famílias buscam água na cidade de Cametá para o consumo. Outras ainda consomem água de cacimba.

\section{IV.1.1.1 FONTES DE ÁGUA PARA O CONSUMO/USO NA RESIDÊNCIA - FONTE: LEVANTAMENTO DE CAMPO DO} IATAM (2015):

Rios/Córregos/Igarapés - $83 \%$, Nascente-12\%, Busca na cidade$5 \%$.

Com relação ao tratamento de água, a maior parte dos assentados faz a coagem da água com tecido limpo e 13 famílias fazem a cloração com pingos de hipoclorito de sódio na água a consumir. Ainda há 08 famílias que não fazem tratamento algum sobre a água consumida.

\subsubsection{TRATAMENTO DE ÁGUA PARA CONSUMO -} FONTE: LEVANTAMENTO DE CAMPO DO IATAM (2015):

Sem Tratamento-18\%, Coagem- $45 \%$, Cloração- $25 \%$, Fervura$6 \%$, Filtragem- $6 \%$.

Em relação aos dejetos humanos, das 36 residências visitadas, 30 possuem banheiros sem tratamentos do esgoto sanitário e apenas três possuem as fossas sépticas que são necessárias para o tratamento correto dos dejetos humanos. Essa falta de tecnologias para tratamento de dejetos humanos é umfator primordial na incidência de doenças de veiculação hídricas nas ilhas, uma vez que o consumo de água ou contato direto durante o banho pode provocar tais doenças.

\section{IV.1.1.3 FORMAS DE TRATAMENTO DOS DEJETOS HUMANOS - FONTE: LEVANTAMENTO DE CAMPO DO IATAM (2015)}

Sem Tratamento-77\%, Fossa Simples-3\%, Fossa Séptica9\%, Foss a Incompleta/Foss a Negra-11\%.

Quanto à destinação do lixo, a parte orgânica é utilizada para a alimentação de animais. O lixo inorgânico, é, na maioria das residências queimado ou enterrado. Uma família citou que vende alguns resíduos recicláveis. A falta de políticas de destinação de lixo por parte do poder público obriga que as comunidades rurais do Município de Cametá garantam a destinação incorreta dos resíduos, causando impactos diretos sobre as diversas matrizes ambientais: água, solo, biodiversidade e o ar.
No que se refere aos problemas ambientais, a maior parte dos entrevistados citou o as soreamento dos rios, a poluição dos rios e o depósito de lixo a céu aberto. Todos esses aspectos geram impactos negativos e levantam longos debates nas reuniões do PAE, onde os agricultores indicam a necessidade de pesquisas e projetos que ataquem diretamente esses problemas.

\section{IV.1.1.4 PROBLEMAS AMBIENTAIS EXISTENTES NOS LOTES - FONTE: LEVANTAMENTO DE CAMPO DO IATAM (2015):}

Assoreamento dos rios-33\%, Poluição dos rios ou nascentes $-19 \%$, Deposição inadequada do lixo-12\%, Erosão-1\%, Queimada-1\%.

\section{IV.1.1.5 PROBLEMAS AMBIENTAIS}

Os problemas ambientais, amplamente discutidos também levantaram a demanda da instalação de um programa de coleta seletiva de lixo semanal na ilha e redondezas.

Os agricultores demonstraram grande interesse em atividades de educação e recuperação ambiental, principalmente relacionadas à conservação da água.

\section{IV.1.2 BIRIBATUBA}

O IATAM realizou entrevistas com 162 famílias de um total de 174 ass sentados exis tente na ilha resultando eminformações abaixo detalhadas [13]. A área geográfica da ilha totaliza 287,4486 ha.

\section{IV.1.2.1SAÚDE}

Atualmente os principais serviços de saúde disponibilizados para os assentados se resumem aos agentes comunitários de saúde (ACS) e as campanhas de vacinação. Apesar disso, nem toda a população é atendida pelos ACS.

As principais doenças citadas que acometem os agricultores foram o diabetes, viroses e dores no corpo e febre.

\section{IV.1.2.2 SANEAMENTO}

A principal fonte de água para o uso doméstico na residência é dos rios. São 117 famílias que utilizam diretamente água dos rios no dia-a-dia. Algumas famílias buscam água na cidade para o consumo, outras que moram na Vila ou próximo utilizam água encanada pública.

Principais formas de tratamento de água: Sobre o tratamento de água, destaque para a coagem em pano-54 famílias, a cloração por meio de adição de hipoclorito de sódio-37 famílias, outras formas que incluem a adição de sulfato de alumínio também são praticados por 11 famílias, mas há 60 famílias que não fazem nenhum tratamento na água.

\section{IV.1.2.3 DESTINAÇÃO DE LIXO E DEJETOS HUMANOS}

O lixo, também um grave problema, não possuindo destinação adequada, pois o lixo não orgânico é queimado em 157 residências. Já o lixo orgânico familiar é disponibilizado aos animais.

Os dejetos humanos se constituem um dos maiores problemas de saneamento e saúde, posto que não há tratamento eficiente e eles acabam chegando aos cursos hídricos, que, como 
citado anteriormente, é ingerido pelas famílias sem tratamento adequado, uma fossa séptica.

Destino dos dejetos humanos/Formas de Tratamento: Sem Tratamento-131, Fossa Simples-9, Fossa Séptica-8, Fossa Incompleta/Fossa Negra-12, Rede de Esgoto, não responderam-2. Não obstante o problema do lixo é umagravante, pois pela falta de coleta de resíduos sólidos estes são queimados ou depostos nos próprios cursos de água. Os veículos aquáticos também poluemos rios com a deposição de óleos combustíveis em suas águas.

O lixo inorgânico poderá ser coletado via um programa de coleta seletiva que uma cooperativa da cidade de Cametá esta desenvolvendo em áreas de terra firme.

\section{IV.1.3 PACAJAÍ I}

Entrevistadas 49 famílias de um total de 57 famílias assentadas dentro de uma área geográfica da ilha totalizando 224,4334 ha. Detalhamento a seguir [14].

\section{IV.1.3.1 SAÚDE}

O PAE não possui postos de saúde. O serviço de agente comunitário de saúde não contempla todas as famílias.

Principais doenças e problemas de saúde identificados pela entidade de ATER: Dores na cabeça ou no corpo, hepatite, viroses, verminoses, febre, gastrite, problemas estomacais/intestinais.

No ano 2012 houve uma epidemia de malária com 217 casos confirmados no PAE e nas proximidades, nesta ocasião houve ações da Secretaria de Saúde que distribuiu mosqueteiros para rede e para a cama e fez um processo de pulverização na área para combater o mosquito transmis sor. Os agricultores informaram também que entre os anos 2012 e 2014 ocorreram dezenas de cas os de hepatite, mas os dados não são oficiais.

\section{IV.1.3.2 SANEAMENTO}

Em se tratando de água para o uso na residência, a principal fonte é dos rios -45 famílias e o restante de outras formas. A forma de tratamento da água mais comum no PAEé coagem com pano, mas há famílias que fazem uso da cloração por meio de adição de hipoclorito de sódio na água apanhada do rio. Foi identificada também a filtração da água em filtros de barro, a fervura e o uso de sulfato de alumínio como tratamento da água para o consumo.

Principais formas de tratamento de água: Coagem-33, Cloração-13, outros-3.

Ao seremquestionados se a água dos rios é suficiente para o uso na residência, a maior parte dos entrevistados (65\%) respondeu negativamente. Isto porque não há tratamento para consumo humano e das atividades domesticas, bem como o movimento das marés também impede em alguns momentos disponibilidade de água medianamente limpas para lavagem de roupas e outros serviços.

\section{IV.1.3.3 DESTINAÇÃO DE LIXO E DEJETOS HUMANOS}

Conforme se nota na figura 4, os dejetos humanos não tem tratamento e/ou destinação adequados em 46 das 49 residências, o que tambémé fator de reclamação quanto à dis ponibilidade de água para consumo doméstico. Em três residências possuem fossa negra e/ou incompleta. Este problema é grave e coloca em risco a saúde e a vida das famílias assentadas e deverá ser discutido em outros fóruns de debate e outras discussões de políticas públicas, haja vista, incomodar pessoas de todas as idades, conforme mostra figura 5.

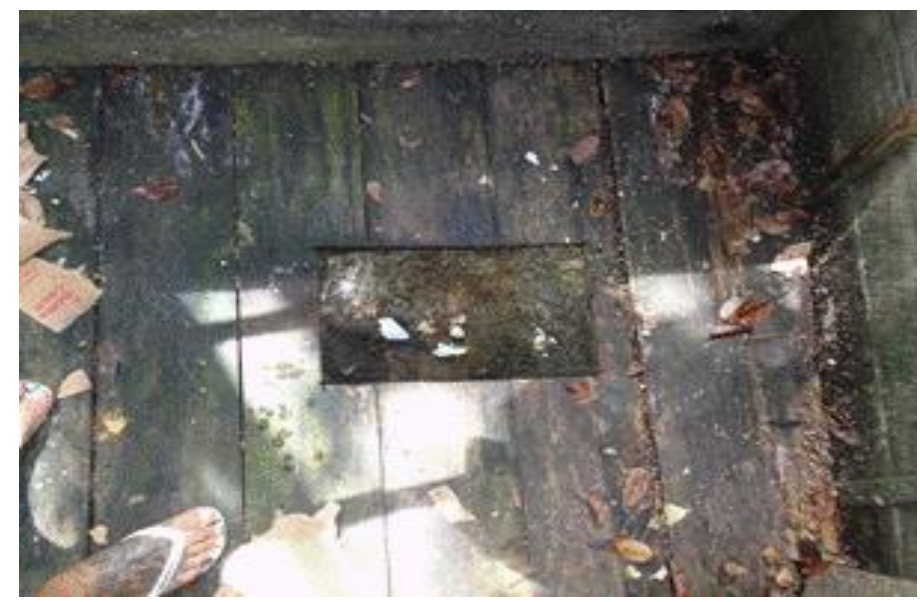

Figura 5: de Banheiro sem Tratamento - PAE Pacajaí I. Fonte: IATAM, (2015).

O lixo produzido no PAE tem dois destinos: o orgânico é dado aos animais para a sua alimentação e o não orgânico é queimado no lote. As famílias reivindicam coleta de lixo regular.

\section{IV.1.3.4 PROBLEMAS AMBIENTAIS}

No que concerne aos problemas ambientais existentes nos lotes, a maioria dos entrevistados citou a assoreamento dos rios, poluição dos rios ou nascentes e deposição inadequada do lixo e a erosão como os maiores problemas nos lotes. Outros problemas: Contaminação do Solo, Desmatamento e Queimada.

\section{IV.1.4 CACOAL}

Entrevistadas 253 famílias de um total de 298 famílias ass entadas. Área total do PAE perfazendo 520,18 ha. Abaixo apresentam-se as informações coletadas pelo IATAM [15].

\section{IV.4.1.4.1 SAÚDE} do IATAM.

Não há posto de atendimento à s aúde, segundo o relatório

Ocorrem campanhas de vacinação e visitas de Agentes Comunitários de Saúde ao PAE, segundo os relatos coletados nas entrevistas do IATAM. São três profissionais que atendem as famílias com visitas regulares, distribuem hipoclorito de sódio para o controle da qualidade de água para consumo humano, distribuem preservativos para controle de natalidade, fazem controle de pesagem de crianças.

Doenças de infecção estomacal e intestinal, viroses, doenças respiratórias e crônicas foram as mais listadas pelos extrativistas.

Principais problemas de saúde identificados: Asma, Diabetes, Febre, Verminoses, Hipertensão/Hipotensão, Viroses, Hepatite, Anemia, Colesterol Alto ou Baixo, Diarreia/Vômitos, Dores na cabeça ou no corpo, Problemas Estomacais ou intestinais, Gastrite.

Algumas dessas doenças estão intrinsecamente ligadas à falta de saneamento básico, es pecialmente aquelas relacionadas ao consumo ou contato com água contaminada por pató genos. 


\section{IV.1.4.2 SANEAMENTO}

O saneamento básico envolve o conjunto de serviços de infraestrutura de abastecimento e tratamento de água, manejo de resíduos sólidos, esgotamento sanitário e ainda manejo de água da chuva [16].

No concernente à água para o uso na residência, a principal fonte é dos rios, no entanto, algumas famílias buscam água na cidade de Cametá para o consumo, pois entendem que a água do rio não atende os parâmetros de qualidade para sua saúde, porém ficam preocupados, pois quando as crianças estão na escola não tem aces so à água tratada.

As formas de tratamento da água listadas pelos agricultores, têm se demonstrado insuficientes ao objetivo, pois não chegam a garantir potabilidade da água para consumo. A maior parte dos assentados faz a coagem da água e cloração e quatro famílias utilizam hipoclorito de sódio na água depois de coada.

Principais Formas de Tratamento de Água para consumo: coagem-179, outros-cloração, sem tratamento, cloração, fervura, filtragem.

\section{IV.1.4.3 DESTINAÇÃO DE LIXO E DEJETOS HUMANOS}

A maioria das residências visitadas não possui tratamentos do esgoto sanitário-239, um morador relatou possuir uma fossa simples e três famílias informaram dar outra destinação aos resíduos, se referindo a buracos feitos no fundo dos lotes onde a água não alcança em maré alta, o que eles consideram uma maneira diferente de cuidar dos dejetos, que não se encaixa em nenhum modelo de fossa.

Os banheiros são casinhas feitas em madeira e os dejetos humanos são jogados diretamente sobre o solo e/ou água; quando a maré está alta piora a situação, pois o fluxo de maré carrega as fezes para o rio, poluindo a água do mesmo; a falta de tecnologias para tratamento de dejetos humanos é um fator primordial para incidência de doenças de veiculação hídrica nas ilhas.

Quanto aos resíduos sólidos, a principal destinação do lixo orgânico é a alimentação de animais, sendo também utilizado para compostagem. Existem cinco famílias que relataram queimar esse tipo de lixo. O lixo não orgânico, é queimado pela maioria das famílias ou é descartado no rio. A falta de políticas públicas na gestão de resíduos sólidos obriga os assentados a realizarem destinação incorreta dos resíduos causando impactos diretos sobre as matrizes ambientais: água, solo, biodiversidade e o ar.

\section{IV.1.4. 4 PROBLEMAS AMBIENTAIS}

A maioria dos entrevistados apontou o assoreamento dos rios como problema ambiental mais incidente do PAE, seguido da poluição dos rios ou nascentes, deposição inadequada do lixo, erosão, contaminação do solo, desmatamento e queimada.

\section{IV.1.5 JACAREUÁ}

Entrevistadas 143 famílias de um total de 196 famílias assentadas, para uma área total de 773,5151 ha. Os dados descritos seguem abaixo [17].

Entre os serviços de saúde disponibilizados no PAE, é mais comum relatos de realização de campanhas de vacinação e presença cotidiana dos profissionais Agentes Comunitários de Saúde, pois não há posto de saúde. Os serviços destes últimos são basicamente a realização de visitas regulares, distribuição de preservativos para controle de natalidade, distribuição de hipoclorito de sódio para tratamento da água, fazem controle de pesagem de crianças e direcionamento de doentes crônicos para acompanhamento e monitoramento no hospital na sede urbana de Cametá.

Relatos sobre as maiores incidências de problemas de saúde indicam problemas respiratórios e viroses. As principais doenças crônicas encontradas: hepatite, que pode está relacionada ao consumo de água de má qualidade, haja vista que muitas famílias consomem água diretamente do rio e com pouco ou nenhum tratamento, hipertensos e diabéticos.

\section{IV.1.5.1 SAÚDE}

Principais problemas de saúde/Principais doenças crônicas: hepatite, hipertensão/hipotensão, colesterol, diabetes.

Outras doenças e problemas de saúde considerados menos preocupantes e, que raramente fazem com que os agricultores procurem ajuda médica: Gripes e viroses estão entre os problemas de saúde mais comum. Viroses e gastrite, gripe e anemia, febre, problema estomacais e dores na cabeça/corpo.

\section{IV.1.5.2 SANEAMENTO}

A fonte mais utilizada se refere aos rios, inclusive para o consumo, no entanto, algumas famílias buscam em um distrito ou na Cidade de Cametá para o consumo. Há moradores que se beneficiam do sistema de rede pública via poço artesiano instalado em um distrito.

Não há relatos de tratamento de água eficaz em relação aos problemas de falta de saneamento básico, pois a coagem e cloração realizadas na maioria das casas não é realizada de maneira correta no sentido de garantir a potabilidade da água para consumo. De toda forma, apres entam-se os relatos de tratamento de água que os agricultores realizam. Via de regra eles usam mais uma medida dessas, por exemplo, coa e ferve, ou coa e filtra, ou filtra e uso o cloro. Inclusive, o tratamento de água para consumo e cozimento de alimentos é uma demanda apresentada pelas famílias a equipe de ATER junto com outros órgãos públicos possam buscar soluções palpáveis, além da implantação de um sistema de abastecimento de água para o PAE.

\section{IV.1.5.3 DESTINAÇÃO DE LIXO E DEJETOS HUMANOS}

Outro grande problema de saúde e meio ambiente relacionados, diz respeito ao tratamento dos dejetos humanos, pois das 143 residências visitadas, 133 não realizam nenhum tratamento e as demais informaram uma destinação de dejetos, que efetivamente também não trazem resultados positivos, ou dão destinação adequado, de forma que essa falta de tecnologias para tratamento de dejetos humanos é um fator primordial para incidência de doenças de veiculação hídrica nas ilhas, uma vezque o consumo de água ou contato direto durante o banho podem provocar doenças.

O lixo, problema que deverá virar matéria prima para artesanato e ser elemento para capacitação sobre sua melhor destinação, pois já fora solicitado serviços de ATER nesse sentido, bem como fora solicitado serviço de coleta regular de lixo reciclável. A Situação está sendo negociada coma Cooperativa de Recicladores de Cametá, via IATAM (prestadora de ATER). A principal destinação do lixo orgânico é para a alimentação de 
animais-137 e o lixo não orgânico circula pelos rios-8 ou é queimado/enterrado-134.

\section{IV.1.5.4 PROBLEMAS AMBIENTAIS}

Em referências aos problemas ambientais existentes nos lotes, a maioria dos entrevistados-120 famílias citou o assoreamento dos rios, seguido da poluição dos rios-98 famílias, deposição inadequada do lixo-54 famílias, erosão-20 famílias, contaminação do solo-14 famílias, desmatamento-3 famílias e queimadas -3 famílias.

\section{IV.1.5 - ITAÚNA}

Abaixo são exibidas as informações oriundas das entrevistas realizadas com 275 famílias de um total de 336 [18].

O PAE possui uma área total de 1.120,5409 ha.

\section{IV.1.6.1 SAÚDE}

Os moradores não têm estruturas de atendimento em saúde dentro da localidade. Internamente são disponibilizados os serviços de dois Agentes Comunitários de Saúde, que visitam, entregam hipoclorito de sódio, orientam sobre o uso da água e agendam consultas de rotina e odontológicas na zona urbana e as campanhas de vacinação de crianças e animais.

Os principais problemas descritos foram as hepatites, pressão alta ou baixa e diabetes. Outros problemas como viroses, gastrenterites, anemia, malária, gastrite, hemorragia, amebíase, dengue, dermatite crônica, problema de pele.

\section{IV.1.6.2 SANEAMENTO}

Em se tratando de água para o uso na residência, a principal fonte é dos rios, ou seja, a maioria das famílias utiliza a água do rio para uso da residência, inclusive para o consumo, no entanto, uma grande parte das famílias busca água na Cidade de Cametá para o consumo.

Não há relatos de tratamento de água eficaz em relação aos problemas de falta de saneamento básico, pois a coagem e cloração realizadas na maioria das casas não é realizada de maneira correta no sentido de garantir a potabilidade da água para consumo. Inclusive, o tratamento de água para consumo e cozimento de alimentos é uma demanda apresentada pelas famílias para que equipe de ATER junto com outros órgãos públicos possam buscar soluções palpáveis, além da implantação de um sistema de abastecimento de água para o PAE. Todas as famílias que dis seram tratar a água antes de consumir citaram utilizar mais de um método de tratamento.

\section{IV.1.6.3 DESTINAÇÃO DE LIXO E DEJETOS HUMANOS}

Em relação aos dejetos humanos, 230 residências não oferecem destinação adequada aos seus dejetos, pois os banheiros são aqueles do tipo casinha e não dispõem de fossas sépticas.

Formas de tratamento de dejetos humanos: sem tratamento-230, fossa simples-34, foss a incompleta/fos sa negra-6, fossa séptica-5.

Já com relação ao lixo, as famílias queimam e/ou disponibilizam para os animais os resíduos do lote. Os resíduos não orgânicos (plásticos, metais, vidros, papel e etc.) são queimados; os orgânicos (restos de comida, restos vegetais e etc.) são jogados no lote para a alimentação dos animais. Todos os produtos listados no lixo podem e devem ser reaproveitados após capacitações que os agricultores solicitaram para a equipe de ATER. Algumas famílias utilizam restos alimentares nas plantas, enterram ou jogam nos quintais e outras levam vidros e latas para vender na cidade.

\section{IV.1.6.4 DESTINAÇÃO DE LIXO E DEJETOS HUMANOS}

Formas de deposição do lixo/Destino do lixo:

- não orgânico: queimado-271, enterrado-2, outros-2.

- orgânico: queimado-265, outros-10.

Em relação aos problemas ambientais existentes nos lotes, a maioria citou a poluição dos rios o assoreamento dos rios, deposição inadequada do lixo como os maiores problemas nos lotes.

\section{IV.1.6.5 PROBLEMAS AMBIENTAIS}

Problemas ambientais existente no lote: poluição/contaminação de nascentes -rios-córregos, as soreamento de rios/córregos/igarapés, deposição de lixo de forma inadequada (a céu aberto), contaminação do solo por uso de agrotóxicos/destinação inadequada de embalagens, desmatamentos, queimadas, outros.

Quanto ao meio ambiente lideram como preocupações dos moradores, os resíduos sólidos, os dejetos humanos e as soreamento.

Percebe-se que a falta de estrutura sanitária denota possibilidade de contaminação do solo e água nestes ambientes, fato esse corroborado por [19] que em seu estudo concluiu ser necessária adoção de medidas no sentido de conscientizar a população de assentamento rural na Amazônia Brasileira sobre práticas danosas ao meio ambiente e como consequência o próprio bem-estar dessas pessoas.

\section{CONCLUSÃO}

A partir dos resultados analisados é possível afirmar que:

- há possibilidade de estas enfermidades relatadas pelos ribeirinhos possuírem uma relação direta ou indireta com os problemas ambientais informados pelos próprios moradores dos PAE's objeto do estudo.

- o uso de práticas inadequadas e não condizentes com a sustentabilidade contribui para a degradação ambiental que compromete a saúde, a recreação, a vivência cotidiana, a economia e as atividades produtivas.

- o diagnóstico elaborado serve de subsídio para adoção de mecanismos mais eficazes de informação, monitoramento, controle, fiscalização conjunta do INCRA com os órgãos ambientais e de saúde, buscando reforçar o cumprimento da legis lação ambiental.

\section{AGRADECIMENTOS}

Ao INCRA pela disponibilidade de dados para elaboração des te trabalho. Ao Eng ${ }^{\circ}$ Civil e Sanitarista/Ambiental Marcelo José Cunha Arbage pela confecção do Mapa de Localização dos PAE na Microrregião de Cametá. 


\section{REFERÊNCIAS}

[1] INCRA. Diretoria de Assentamento. Projetos de Assentamento Agro-Extrati vistas. Brasília, s/d.

[2] BRASIL. Decreto-Lei $\mathbf{n}^{\circ}$ 1.110. Cria o Instituto Nacional de Colonização e Reforma Agrária (INCRA), extingue o Instituto Brasileiro de Reforma Agrária, o Instituto Nacional de Desenvolvimento Agrário e o Grupo Executivo da Reforma Agrária e dá outras providências. Brasília, 09/07/1970.

[3] INCRA. Competências. Disponível em: http://www.incra.gov.br/competencias. Acesso em: 18/jun./2016.

[4] LE TORNEAU \& BURSZTYN, M. Assentamentos rurais na Amazônia: contradições entre a política agrária e a política ambiental. Ambiente e Sociedade, Campinas, v.13, n.1, p.111 a 130, 2010.

[5] Alcântara, J.V. Saúde ambiental de ribeirinhos no Baixo Acará. 2008. 135 f. Dissertação (Mestrado em Planejamento do Desenvolvimento Sustentável do Trópico Úmido) - Núcleo de Altos Estudos Amazônicos da Universidade Federal do Pará. Belém-PA.

[6] SANTOS, E. C. O., et al. Exposição ao mercúrio e ao arsênio em Estados da Amazônia: síntese dos estudos do Instituto Evandro Chagas/FUNASA. Rev. Bras. Epidemiol. V. 6, No 2, p 171-185, 2003.

[7] FERREIRA, M. J. M., VIANA, M.M. A expansão do agronegócio no semiárido cearense e suas implicações para a saúde, o trabalho e o ambiente. Interface, Botucatu-SP, V.20, $\mathrm{N}^{\mathrm{o}}$ 58, p 649-60, 2016.

[8] BARBOSA, C. S., et al. Turismo de risco para esquistossomose mansônica em Porto de Galinhas, Estado de Pernambuco, Brasil. Rev. Pan-Amaz. Saúde, Belém-PA,v. 6, nº 1, p 51-58. 2015.

[9] SILVA, A. F. S., et al. Análise bacteriológica das águas de irrigação de horticulturas. Rev. Ambient. Água, Taubaté, v. 11 nº 2, p 428-438, Apr. / Jun. 2016.

[10] 2016.2 Disponível em: http://www.cidades.ibge.gov.br/v3/cidades/municipio/1502103.

Acesso em 15/jun./2016.

[11] ARNAUD, M. J. C. Gestão Ambiental no Baixo Tocantins: dos movimentos ambientalistas à elaboração do PPDJUS. Dissertação (Mestrado) - Instituto de Filosofia e Ciências Humanas, Universidade Federal do Pará. 136p. 2010.

[12] INCRA/IATAM. Autodiagnóstico PAE Ilha Pacajaí II. Cametá, 2015.

[13] INCRA/IATAM. Autodiagnóstico Projeto de Assentamento Agroextrativista Ilha Biribatuba. Cametá, 2015.

[14] INCRA/IATAM. Autodiagnóstico PAE Ilha Pacajaí I. Cametá, 2015.
[15] INCRA/IATAM. Diagnóstico Socioeconômico e Ambiental PAE Ilha Cacoal. Cametá, 2015.

[16] LELIS, M.P.N. Plano de Saneamento básico. Rio de Janeiro: 2011. Disponível em: http://www.bndes.gov.br/SiteBNDES/export/sites/default/bndes_ pt/Galerias/Arquivos/empresa/download/apresentacoes/pmat/9ap1 _Plano_Saneamento_junho_2011_RJ.pdf. Acesso em 16/10/2016.

[17] INCRA/IATAM. Autodiagnóstico PAE Ilha Jacareuá. Cametá, 2015.

[18] INCRA/IATAM. Autodiagnóstico PAE Ilha Itaúna. Cametá, 2015.

[19] SILVA, H.C.H; et al. A qualidade do saneamento ambiental no assentamento rural Amparo no município de Dourados-MS. Soc. Nat., Uberlândia-MG, v.26, no.3, Sep.Dec.2014. 